\title{
COMPARISON BETWEEN PRENATAL AND PERINATAL IMAGING AND FOETAL AUTOPSY RESULTS IN A TERTIARY CARE HOSPITAL IN SOUTH INDIA
}

\author{
Shali A. S1, Feroze $M^{2}$
}

${ }^{1}$ Assistant Professor, Department of Pathology, Government Medical College, Calicut.

${ }^{2}$ Professor, Department of Pathology, Government Medical College, Trichur.

\begin{abstract}
BACKGROUND

Evaluation of a congenital anomaly starts from antenatal period by the assessment of the maternal and family risk factors and ultrasonogram evaluation. Postnatal evaluation includes morphologic, radiologic, histopathological and karyotypic studies with investigations for infectious, genetic and metabolic causes. Although, some anomalies can be detected by ultrasonogram and xrays, a foetal autopsy has to be done to confirm the diagnosis and look for associated anomalies.

Objectives- To assess the efficacy of foetal autopsy over prenatal ultrasound and post-mortem x-ray examination.
\end{abstract}

\section{MATERIALS AND METHODS}

This is a descriptive study, the sample of which includes all anomalous foetuses delivered between $1^{\text {st }}$ January 2011 and $31^{\text {st }}$ December 2012 that took place in Institute of Maternal and Child Health, Calicut Medical College during a two-year period.

\section{RESULTS}

The ultrasonogram correlation with the autopsy findings were done as per the categories described by Isaksen et al. Full agreement was obtained in $44.6 \%$ of cases in our study. Out of 43 cases with x-rays, 28 of them did not show any abnormality. 15 cases which showed abnormality correlated with the morphological findings after autopsy.

\section{CONCLUSION}

While diagnostic imaging techniques is the best available tool to assess foetal anomalies in the prenatal life. It cannot give a complete assessment of the foetal anomalies. Autopsy examination is strongly recommended for identifying the cause of foetal loss.

\section{KEYWORDS}

Foetal Autopsy, Congenital Anomalies, Foetal Ultrasound Scanning, Histopathology.

HOW TO CITE THIS ARTICLE: Shali AS, Feroze M. Comparison between prenatal and perinatal imaging and foetal autopsy results in a tertiary care hospital in South India. J. Evolution Med. Dent. Sci. 2017;6(44):3427-3431, DOI: 10.14260/Jemds/2017/743

\section{BACKGROUND}

The autopsy has been a powerful tool in clinical medicine as far back as the 15th century. However, providing authorisation for the autopsy of a relative has always been a stressful experience for any family member, more so authorising the autopsy of a new-born baby.

The ignorance about the benefits and cost constraints unfortunately lead to reluctance towards autopsy. A study done by Saller DN et al in 1995[1] showed that autopsy added significantly to the clinical diagnosis in $44.7 \%$ of the cases. In $55.3 \%$ cases, the antenatal diagnosis was confirmed on autopsy. In 1996, an Indian study done by Rajashekar et al ${ }^{2]}$ found that autopsy added to or changed the pre-existing diagnosis in $59.5 \%$ of the cases.[1],[2],[3] This study has tried to analyse the causes of in utero foetal demise and the utility of perinatal autopsy in identifying the cause of death. The diagnostic accuracy of an antenatal ultrasound was also assessed, comparing it with the autopsy findings.

Ultrasound examination during pregnancy is considered to be an important part of prenatal care, as it may reveal foetal developmental anomalies.[3],[4]

Financial or Other, Competing Interest: None.

Submission 18-04-2017, Peer Review 21-05-2017,

Acceptance 27-05-2017, Published 01-06-2017.

Corresponding Author:

Dr. Shali A. $S$,

Brindavan, Chevayoor, Calicut.

E-mail: shalidr@gmail.com

DOI: $10.14260 /$ jemds $/ 2017 / 743$
The option of routine antenatal ultrasonographic examination for all pregnant women has increased the detection rate of foetal anomalies.[5] When a serious anomaly is suspected prenatally, some parents request termination of pregnancy. This request may be based on the results of investigations that imply that the baby will almost certainly have a lethal anomaly, eg. anencephaly or one likely to cause long-term morbidity as in spina bifida. In other instances, termination of pregnancy may be requested when the implications of the investigations are less clear, for examplea foetus with mild cerebral ventriculomegaly. After termination of pregnancy, most parents would like to know if the prenatal prediction was accurate and its implications for future pregnancies. These findings are critical and need confirmation and are obtained from the autopsy examination. Moreover, foetal autopsy may provide additional information to that obtained by ultrasonography, which is important for accurate genetic counseling. ${ }^{[6]}$

Since very few studies have been documented in India regarding the distribution of the congenital malformations, this study will give a comparison of the congenital malformations detected prenatally by ultrasonography and postnatally by radiography with the morphological findings at foetal autopsy and also the quantum of additional information autopsy can provide.

\section{MATERIALS AND METHODS}

All foetuses of medically terminated pregnancies during second and third trimesters and foetal deaths in the early neonatal period that took place in Institute of Maternal and 
Child Health, Calicut Medical College during a two-year period from January 2011 to December 2012 were included in the study. This is a descriptive and prospective study. Analysis was done on 49 autopsies.

When the specimens were received from Department of Obstetrics and Gynaecology, Calicut Medical College, all the data regarding the previous pregnancy, maternal age, gestational week at the time of USG diagnosis, termination of pregnancy if any, medical history and family history were collected from the patient's records. Consent was taken from the parents.

After general examination, photographs of the external appearance were taken in all cases. Radiological evaluation with x-ray was done whenever possible and the findings recorded. After grossing representative bits were taken from all organs, slides were prepared with haematoxylin and eosin stain and used to correlate with gross morphology. A correlation of findings was done with the autopsy findings and ultrasound examination. The correlation of ultrasound and autopsy findings was categorised into groups (categories $1-4$ ) according to a modification of the method described by Isaksen et al.[7]

1. Full agreement between the ultrasound and autopsy findings.

2. Minor autopsy findings not found or not recorded at the ultrasound examination.

3. Major autopsy findings not detected at the ultrasound examination, although other ultrasound findings indicated termination of pregnancy.

4. No autopsy findings suspected at the ultrasound examination. In these cases, the foetus or infant deceased naturally in utero or shortly after birth.

Results are expressed in percentage. Ultrasound findings are compared using sensitivity and specificity.

\section{RESULTS}

X-ray was taken in 43 cases; 28 cases did not show any radiological abnormality. The abnormalities detected are given in the table below. The skeletal dysplasias showed good correlation with the morphological findings.

\begin{tabular}{|c|c|c|}
\hline Finding & No. of Cases & Percentage \\
\hline Thorax & 6 & 13.9 \\
\hline Diaphragmatic Hernia & 1 & \\
\hline Short ribs & 2 & \\
\hline Lung Hypoplasia & 2 & \\
\hline Cardiomegaly & 1 & \\
\hline Skull and Spine & 4 & 9.3 \\
\hline Hemivertebrae & 2 & \\
\hline Kyphoscoliosis & 1 & \\
\hline Anencephaly & 1 & \\
\hline Limbs & 5 & 11.6 \\
\hline Bowing of long bones & 2 & \\
\hline Polydactyly & 1 & \\
\hline Talipes equinovarus & 1 & \\
\hline Ectrodactyly & 1 & \\
\hline \multicolumn{3}{|c|}{ Table 1. X-Ray Findings } \\
\hline
\end{tabular}

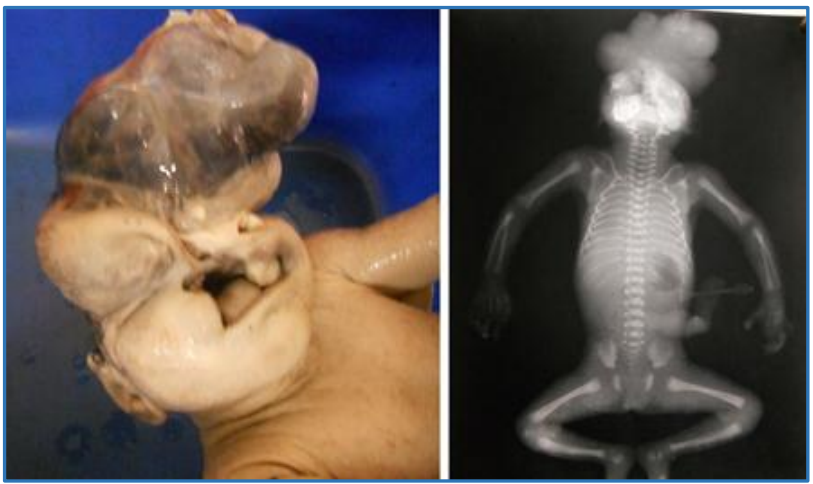

Figure 1. Anencephaly with Cleft Lip, Cleft Palate and Placenta adhered to Scalp
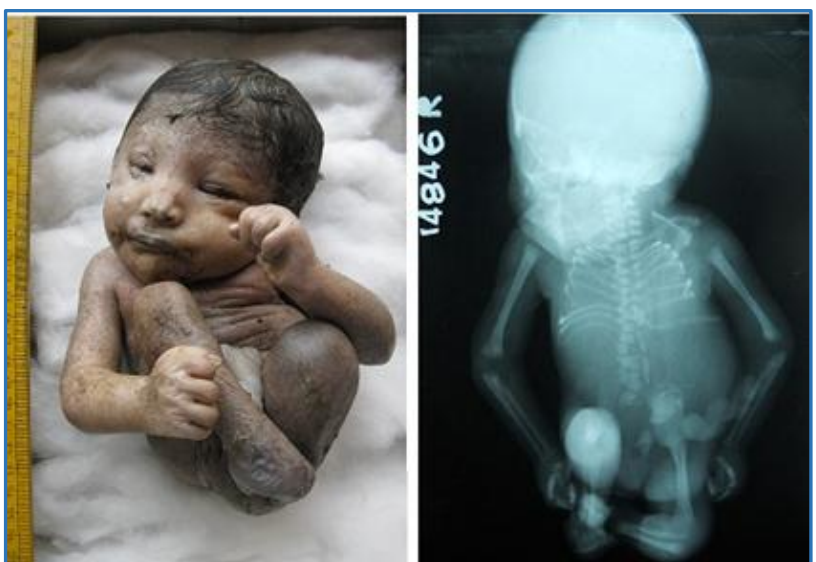

Figure 2. X-Ray showing Multiple Hemivertebrae and Less Number of Ribs
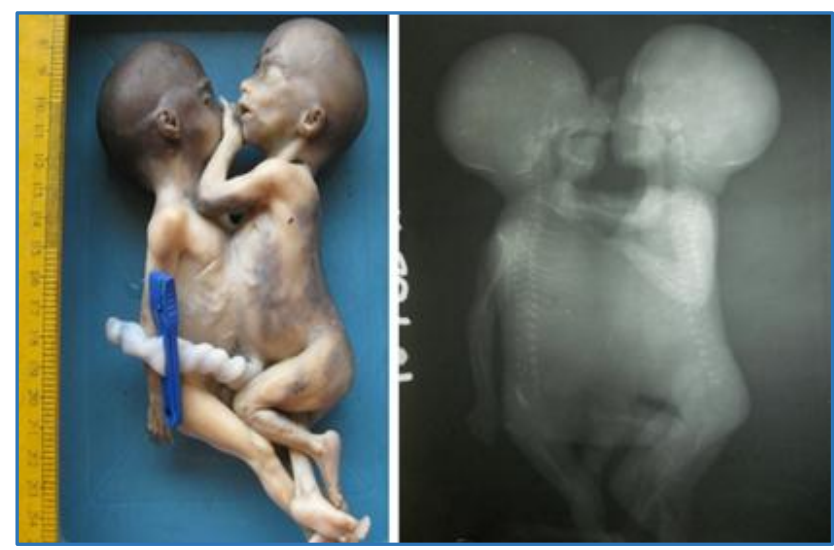

Figure 3. Thoraco-omphalopagus

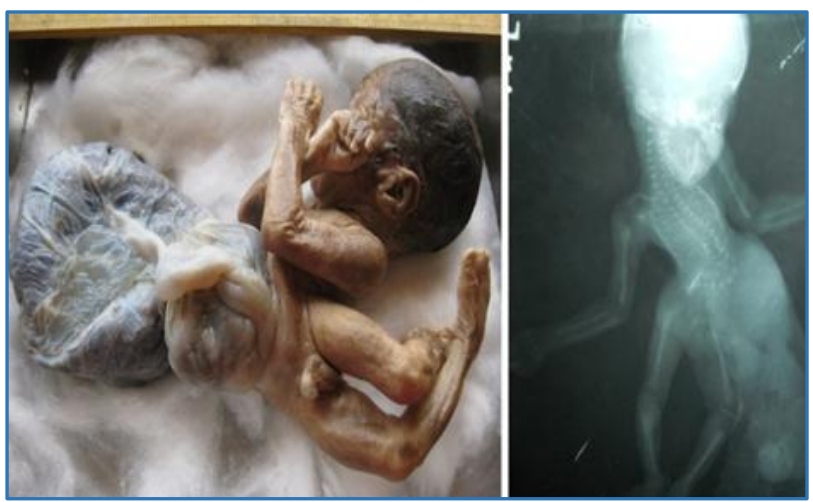

Figure 4. Omphalocele with Lumbar Kyphoscoliosis 
Correlation between Ultrasonographic and Autopsy Findings-

The correlation of ultrasound and autopsy findings was categorised into 4 groups according to a modification of the method described by Isaksen et al.[7]

The findings in each category is given in the table below.

\begin{tabular}{|c|c|c|}
\hline Anomalies & Number & $\mathbf{\%}$ \\
\hline Head, Neck and Spine & $\mathbf{7}$ & $\mathbf{1 4 . 2}$ \\
\hline Hydrocephalus & 3 & \\
\hline Meningocoele & 1 & \\
\hline Anencephaly & 1 & \\
\hline Spina bifida & 1 & \\
\hline Cleft palate & 1 & \\
\hline Thoracoabdominal & $\mathbf{7}$ & $\mathbf{1 4 . 2}$ \\
\hline Lung hypoplasia & 2 & \\
\hline Cardiac defects & 2 & \\
\hline Cystic mass in abdomen & 1 & \\
\hline Thoraco-omphalopagus & 1 & \\
\hline Diaphragmatic hernia & 1 & \\
\hline Renal Anomalies & $\mathbf{3}$ & $\mathbf{6}$ \\
\hline Renal agenesis & 2 & \\
\hline ARPKD & 1 & \\
\hline Limb Anomaly & $\mathbf{3}$ & $\mathbf{6 . 1 2}$ \\
\hline Hydrops Foetalis & $\mathbf{2}$ & $\mathbf{4 . 0 8}$ \\
\hline Total & $\mathbf{2 2}$ & $\mathbf{4 4 . 9}$ \\
\hline \multicolumn{2}{|c|}{ Table 2. Category 1 } \\
\hline
\end{tabular}

\begin{tabular}{|c|c|c|}
\hline Anomalies & Number & \% \\
\hline Small intestinal stenosis & 1 & \\
\hline Single umbilical artery & 2 & \\
\hline $\begin{array}{c}\text { Renal cyst with single atria and } \\
\text { ventricle }\end{array}$ & 1 & \\
\hline Absent kidney L & 1 & \\
\hline Congenital lobar emphysema & 2 & \\
\hline Spinal haemangioma & 1 & \\
\hline Haemangioma scalp & 1 & \\
\hline Renal agenesis B/L & 1 & \\
\hline Placental infarct & 1 & \\
\hline Placental necrosis & 1 & \\
\hline Total & $\mathbf{1 2}$ & $\mathbf{2 4 . 5}$ \\
\hline \multicolumn{2}{|c|}{ Table 3. Category 2 } \\
\hline
\end{tabular}

\begin{tabular}{|c|c|c|}
\hline Anomalies & Number & $\%$ \\
\hline Storage disorder & 1 & \\
\hline $\begin{array}{l}\text { Ventricular hypertrophy with } \\
\text { placental haematoma }\end{array}$ & 1 & \\
\hline Ventricular hypertrophy & 1 & \\
\hline Cleft palate and lip & 1 & \\
\hline Synpolydactyly & 1 & \\
\hline Lymphangioma & 1 & \\
\hline Total & 6 & 12.2 \\
\hline \multicolumn{3}{|c|}{ Table 4. Category 3} \\
\hline
\end{tabular}

\begin{tabular}{|c|c|c|}
\hline Anomalies & Number & \% \\
\hline Renal dysplasia & 1 & \\
\hline Foetal hydrops & 1 & \\
\hline Renal cyst & 1 & \\
\hline Single umbilical artery & 1 & \\
\hline Brain malformation & 1 & \\
\hline Microcephaly, Micrognathia & 1 & \\
\hline Cystic hygroma & 1 & \\
\hline Hydronephrosis & 1 & \\
\hline Total Table 5. Category 4 \\
\hline \multicolumn{2}{|c}{} \\
\hline
\end{tabular}

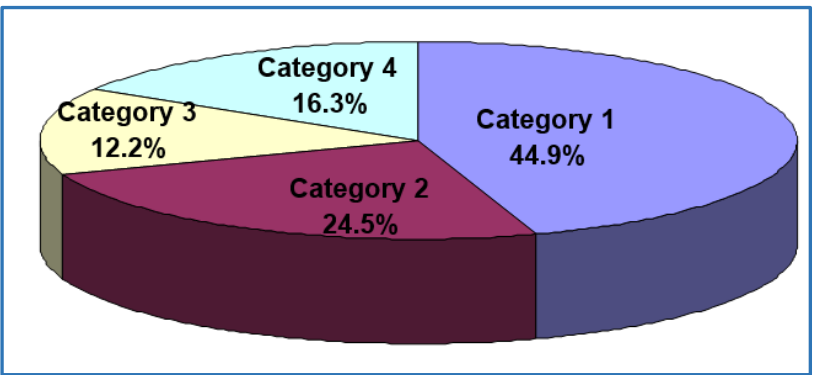

Figure 5. Categorisation of USG Findings

The additional findings that was not demonstrated in the ultrasound, but recorded after foetal autopsy are given in the table below. In 9 such cases, no abnormality was suspected in ultrasound and it was reported as within normal limits.

\section{(Some Cases have more than One Anomaly)}

\begin{tabular}{|c|c|c|}
\hline Finding & Number & $\mathbf{\%}$ \\
\hline Lungs & $\mathbf{5}$ & $\mathbf{1 1 . 1}$ \\
\hline Congenital lobar emphysema & 3 & \\
\hline $\begin{array}{c}\text { Congenital cystic adenomatous } \\
\text { malformation }\end{array}$ & 1 & \\
\hline Lung cyst & 1 & \\
\hline Renal & $\mathbf{2}$ & $\mathbf{4 . 4}$ \\
\hline Renal cyst & 1 & \\
\hline Infantile polycystic kidney disease & 1 & \\
\hline Cardiac Anomalies & $\mathbf{3}$ & $\mathbf{6 . 6}$ \\
\hline Myocardial hypertrophy & 3 & \\
\hline GIT & $\mathbf{5}$ & $\mathbf{1 1 . 1}$ \\
\hline Intestinal stenosis/atresia & 3 & \\
\hline Intestinal infarction & 1 & \\
\hline Liver cyst & 1 & \\
\hline Placental & $\mathbf{3}$ & $\mathbf{6 . 6}$ \\
\hline Placental haematoma & 1 & \\
\hline Placental infarct & 1 & \\
\hline Placental necrosis and calcification & 1 & \\
\hline Others & $\mathbf{5}$ & $\mathbf{1 1 . 1}$ \\
\hline Spinal haemangioma & 1 & \\
\hline Lymphangioma & 1 & \\
\hline Hydorage disorder- liver and heart & 1 & \\
\hline Table 6. Additional Findings after Autopsy & \\
\hline \multicolumn{2}{|c|}{$\mathbf{2}$} \\
\hline
\end{tabular}

\section{DISCUSSION}

In our study, x-rays were taken in 43 cases, 28 of which did not show any abnormality. 15 cases which showed abnormality correlated with the morphological findings after autopsy. Photographs are essential in documenting the presence or absence of any external malformations. There is also a concept of 'limited autopsy' with a photograph and radiograph of the foetus that will help for the diagnosis if other examination is not possible.[8][9] The ultrasonogram correlation with the autopsy findings were done as per the categories described by Isaksen et al.[7] Full agreement was obtained in $44.9 \%$ of cases in our study. Category 3 and Category 4 together formed $28.5 \%$, which includes findings that were not detected at all in ultrasound or findings that were not confirmed in foetal autopsy. Laura Hauerberg et al evaluated the correlation between prenatal diagnosis by ultrasound and autopsy findings based on 52 secondtrimester pregnancies terminated due to foetal malformations or chromosome aberrations diagnosed at a 
gestational age of 12 to 25 weeks.[10] In 24 pregnancies, there was full agreement (Category 1) between ultrasound and autopsy (46\%). In five cases, there was considerable difference $(9.6 \%)$ (Category $3+4$ ). Even when Category 1 matches our results, disagreements between USG and autopsy findings is far less than in our study. Study conducted by Myrte Maessen and Beatrice C. Van Der Matten revealed 95 cases (59\%) with complete concordance (Category 1), which is higher than both studies quoted above; $29 \%$ showed relevant additional information.[11] The rate of discordance (Category 3) was only 1\%, which is much lower than this study. A. Kaasen et al showed full agreement between the ultrasound and the autopsy findings in 160 cases (58.4\%) (Category 1).[12] Discrepancies were found in 114 (41.6\%) pregnancies, of which $86(31.4 \%)$ had autopsy observations that were not detected during the ultrasound examination, and 27 (9.9\%) had ultrasound observations that were not verified at autopsy (Categories 2 and 4 , respectively). Ashutosh Gupta in his study states that $72.5 \%$ cases, there was complete concordance (Category 1) between prenatal and autopsy findings; in 1.09\%, no malformation was found at autopsy (Category 3).[13]

A number of studies have tried to value the diagnostic accuracy of USG examination with very different results. The study conducted by Antonella Vimercati et al showed the 'sensitivity' (i.e. the effectiveness of USG in detecting the anomalies) of USG varies between $14 \%$ and $85 \%$, whereas the specificity (i.e. the ability of USG in correctly diagnosing each malformation) ranges from $93 \%$ to $99 \% .{ }^{[14]}$ In our study, the sensitivity was $47.05 \%$ and specificity $45.45 \%$ which is much lower than the previous study. We have true positivity of $35.5 \%$ and true negativity of $11.1 \%$. Relatively, few studies have assessed the false-positive rate of ultrasound. Martinez-Zamora et al (2007) reported a series of 76 false positives, accounting for $9.3 \%$ of all prenatal diagnoses in their centre.[15] In our study, it was $13.33 \%$. Rossi AC et al in their study showed 3.2\% false positive and $2.8 \%$ false negative cases.[16] In this study, false negativity was $40 \%$ which is much higher.

Routine anomaly scan during antenatal period has become a part of obstetric care and the best time for foetal malformations scan is at around 18 weeks. Even though ultrasonogram can give fairly accurate diagnosis, examination of the terminated foetus for associated anomalies is essential to confirm the diagnosis and look for associated malformations. This is necessary because some associated malformations can be missed or are undetectable on ultrasound. Foetal autopsy, therefore, significantly contributes to the diagnosis of intrauterine foetal death. Saller et al has shown in his study that autopsy added significantly to the clinical diagnosis in $44.7 \%$ of the subjects.[1]

\section{CONCLUSION}

1. X-rays taken before autopsy correlated well in cases with skeletal dysplasias.

2. There was full agreement between ultrasonography and autopsy findings in $44.9 \%$ of cases, in which prenatal USG data was available.
3. In $28.5 \%$ of cases new information was obtained from foetal autopsy, in which USG either could not pick up the anomaly or the findings were not confirmed by autopsy.

4. In our study, the sensitivity was $47.05 \%$ and specificity was $45.45 \%$.

5. Diagnostic imaging techniques cannot give a complete assessment of foetal anomalies. Autopsy examination is strongly recommended for identifying the cause of foetal loss, to verify or improve the prenatal diagnosis and may influence future counseling.

\section{REFERENCES}

[1] Saller DN, Lesser KB, Harrel U, et al. The clinical utility of the perinatal autopsy. JAMA 1995;273(8):663-5.

[2] Rajasekhar S, Bhat BV, Veliath AJ, et al. Perinatal autopsy - a seven year study. Indian J Pediatr 1996;63(4):511-6.

[3] Chitty LS, Hunt GH, Moore J, et al. Effectiveness of routine ultrasonography in detecting fetal structural abnormalities in a low-risk population. BMJ 1991;303(6811):1165-9.

[4] Saari-Kemppainen A, Karjalainen O, Ylostalo P, et al. Ultrasound screening and perinatal mortality: controlled trial of systematic one-stage screening in pregnancy. The Helsinki ultrasound trial. Lancet 1990;336(8712):387-91.

[5] Levi S. Ultrasound in prenatal diagnosis: polemics around routine ultrasound screening for secondtrimester fetal malformations. Prenat Diagn 2002;22(4):285-95.

[6] Boyd PA, Tondi F, Hicks NR, et al. Autopsy after termination of pregnancy for fetal anomaly: retrospective cohort study. BMJ 2004;328(7432):137.

[7] Isaksen CV, Eik-Nes SH, Blaas HG, et al. Fetuses and infants with congenital urinary system anomalies: correlation between prenatal ultrasound and postmortem findings. Ultrasound Obstet Gynecol 2000;15(3):177-85.

[8] Sankar VH, Phadke SR. Clinical utility of fetal autopsy and comparison with prenatal ultrasound findings. J Perinatol 2006;26(4):224-9.

[9] Sharma AK, Phadke SR, Kamboj M, The clinical value of a limited fetal autopsy as illustrated by 2 cases. Aus NZ J Obstetr Gynaecol 1994;34(1):111-3.

[10] Hauerberg L, Skibsted L, Graem N, et al. Correlation between prenatal diagnosis by ultrasound and fetal autopsy findings in second trimester abortions. Acta Obstetricia Gynecologica Scandinavica 2012;91(3):386-90.

[11] Maessen M, van der Matten BC. Correlation between prenatal test results and foetal autopsy findings. Research project performed at CGC Genetics in Porto, Portugal, February-July 2010. Erasmus Journal of Medicine 2011;1(2):14-8.

[12] Kaasen A, Tuveng J, Heiberg A, et al. Correlation between prenatal ultrasound and autopsy findings: a study of second-trimester abortions. Ultrasound Obstet Gynecol 2006;28(7):925-33. 
[13] Phadke SR, Gupta A. Comparison of prenatal ultrasound findings and autopsy findings in fetuses terminated after prenatal diagnosis of malformations: an experience of a clinical genetics center. J Clin Ultrasound 2010;38(5):244-9.

[14] Vimercati A, Grasso S, Abruzzese M, et al. Correlation between ultrasound diagnosis and autopsy findings of fetal malformations J Perinat Med 2012;6(2):13-7.
[15] Martinez-Zamora A, Borrell A, Borobio V, et al. False positives in the prenatal ultrasound screening of fetal structural anomalies. Prenat Diagn 2007;27(1):18-22.

[16] Rossi AC, Prefumo F. Correlation between fetal autopsy and prenatal diagnosis by ultrasound: a systematic review. Eur J Obstet Gynecol Reprod Biol 2017;210:201-06. 